\title{
The relationship between human resource management practices, servant leadership,organizational structure, with organizational commitment:The mediating role of organizational learning capability.
}

\author{
Azharuddin Hashim, Muhammad Firdaus Mohamad Sabri , Mazlina Che Malek, \\ Nadwatul Husna Mustapha \\ Kolej Universiti Islam Antarabangsa Selangor, Bandar Seri Putra, 43000 Kajang, Selangor, Malaysia \\ azharuddin@kuis.edu.my, mohdhakimi@kuis.edu.my, mazlinamalek@kuis.edu.my, nadwatul@kuis.edu.my
}

\begin{abstract}
Organizational learning has aroused a great deal of interest among the academic circles and practitioners as a strategic tool to enhance an organization's core competence and create competitive advantages for success. In extension of organizational learning study, the concept of organizational learning capability had emerged which stress on the importance of the facilitating factors for organizational learning or the organizational propensity to learn. Despite its recognized importance in the literature, little research has been devoted to the research centered on the related factors that could contribute to its development. Factors such as human resource management practices, leadership and organizational structure are identified as the strong predictor of organizational learning. There are also little attention has been given to relate organizational learning with organizational commitment, thus more research is required to analyze the relationships between organizational learning and issues concerning employees, such as organizational commitment.
\end{abstract}

Keywords: Human resource management practices, servant leadership, organizational structure, organizational learning capability, organizational commitment.

\section{INTRODUCTION}

In the organizational context of the new millennium, it is clear that companies need to learn, and the organization's ability to learn is a key strategic capability to compete in modern markets (Santos-Vijande, Lopez-Sanchez \& Trespalacios, 2012).The unpredictable competitive environment, accelerating changes in nature of work setting and fast changing of information technology have all shifted the rules of the business game. As a result, a strategic focus on learning has become a critical in helping organizations to sustain (Smith, 2012). Based on existing research, organizational learning has aroused a great deal of interest, originating from the studies of Argyris \& Schon (1978). The main objective of organizational learning is to enhance an organization's core competence and create competitive advantages for success (Chau, 2008).

\subsection{Background of study}

Despite a cumulative tradition over the years, the organizational learning literature contains very little research on its implementation into practice(Taylor et al., 2010). Because organizational learning is a multidisciplinary topic and consequently has a myriad of diverse definitions, research on getting organizational members to adopt its tenets has been scarce.

Thus, to tackle the changes existing in the practices environment, organizations need to develop a series of specific capabilities and to regenerate their essential competences. From among these resources and capabilities that are specific to the firm, a key role in achieving competitive advantages is played by the intangibles. And, in turn, of all the intangibles, learning, one of the most important capabilities in the society of knowledge, stands out for its highly strategic role (Montes et al, 2005). In the same line, implementing this organizational learning requires a series of characteristics allowing firms to develop the learning processes and, ultimately, become intelligent organizations. Only if they increased their capacity to learn would they be able to survive and adapt to the changing environment (Santos-Vijande et al, 2012). Consequently, organizational learning capability is considered as the organizational and managerial characteristics that facilitate the organizational learning process or allowing an organization to learn, plays an essential role in this process (Chiva et al., 2007).

\section{LITERATURE REVIEW}

Organizational learning is not just the total sum of individual learning but is also the organizational capability to continuously enhance, the collective capacity to reflect, to learn how to learn, to unlearn old ways of doing things and abandon old habits (Senge et al., 1994). In furtherance, the concept of organizational learning capability (Goh \& Richards, 1997; Hult \& Ferrell, 1997) seems to stress the importance of the facilitating factors for organizational learning or the organizational propensity to 
learn. Goh \& Richards (1997, p. 577) define it as the organizational and managerial characteristics or factors that facilitate the organizational learning process or allow an organization to learn. (Akgün et al., 2007) posited organizational learning capability as an ability of firms to implement the appropriate management practices, structures, and procedures that facilitate and encourage learning processes. Chau (2008) noted that the literature generally supports the use of strategic learning capability as the basis for measuring organizational learning. Such capability represents the capacity for organizational members to learn. With the challenges of the organizational learning, a capability to initiate, develop, enhance, and exploit learning in an organization is necessary (Ussahawanitchakit, 2008). Chiva et al. (2007) conceptualized organizational learning capability dimensions into five underlying dimensions, i.e. experimentation, risk taking, interaction with the external environment, dialogue and participative decision making. According to Chiva et al. (2007), these dimensions were considered as the most underlined facilitating factors in the literature.

Now, despite its recognized importance in the literature, little research has been devoted to the research centered on the related factors that could contribute to its development (Rebelo \& Gomes, 2011). Lahteenmaki et al. (2001) asserted that learning itself is seen as a prerequisite for the survival of today's organizations, and so it is quite understandable that there is a growing need to know more about the most favorable conditions for learning. According to Lahteenmaki et al. (2001), filling this knowledge gap is, however, not an easy job. Lopez et al. (2006) asserted that it would be desirable to analyze human resource strategy along with other variables such as organizational structure and leadership. Since all the organizational factors are closely interlinked, the effectiveness of human resource management practices could be determined by the existence of a global approach affecting all areas of an organization.

Furthermore, the relationship between employees' belief regarding learning benefits and employees' commitment is as yet unclear. Chiva, et al. (2007) noted that further research is needed to test the organizational learning capability in other contexts. At the employee level, more research is required to analyze the relationships between organizational learning capability and issues concerning employees, i.e. organizational commitment. Joo \& Park (2010) agreed that while the possible link between organizational learning and organizational commitment has been much discussed, little research has investigated the relationship between the two constructs. It is important to consider the influence of organizational learning on commitment because the process of socialization involves learning which in turn is dependent on the availability of information within an organization (Morrison, 1993). Camps \& Rodríguez (2011) supported that there is a still lack of research on how it is connected to individual task performance although organizational learning capability has been connected to other individual behaviors. They believed this connection is justifiable through organizational commitment.Thus, the conceptual model proposed in this paper goes beyond examining the antecedents of organizational learning. In other words, the consequence and mediating role of organizational learning in influen- cing organizational commitment is another area to be investigated.

\subsubsection{The antecedents of organizational learning capability}

\subsubsection{Human resource management practices}

Although the developments in the field of human resource management practices are now well established in the literature, there is a need to focus on human resource management issues as firms are entering more dynamic international business markets (Lee, Ooi, Chong\&Tan, 2011; Budhwar \& Boyne, 2004). A review of literature on human resource management practices reveals extensive studies on organizational performance and effectiveness, but the association between human resource management practices and organizational learning has not been sufficiently covered in the literature (Kong, Chadee \& Raman, 2012; Theriou \& Chatzoglou, 2008). Jaw \& Liu (2003) posited that as invisible assets are embodied in people, policies regarding human resource management practices and activities are critical to organizational learning. Bhatnagar \& Sharma (2005); Lopez et al. (2005) \& Jerez-Gómez et al. (2005) posited that human resource practices can be a fundamental tool in developing the organization's learning capability, which means that analyzing their possible influence opens a new field of study that has rarely been dealt with. Jerez-Go'mez et al. (2005) argued that there is still debate about how managers can efficiently develop a learning capability in their firms. The learning schools tend to explain the role of human resource management practices as one concerned with the enhancement of an individual capacity to learn (Garavan, 2000). More recent, (Martínez-León \& Martínez-García, 2011) recommended human resource management practices as a future research to link with organizational learning.(Theriou \& Chatzoglou, 2008) pointed out that it is obvious from the literature presented, that best human resource management practices used by an organization have the potential to influence people's attitude towards learning. Khandekar \& Sharma (2005) found that the more specific human resource management practices exist in the organizations, the stronger the learning capability of the organization. Thus, organizational learning capability is strongly "bonded" on human factors which can, as already shown, be strongly shaped or manipulated by those human resource management practices that are usually described as "best human resource management practices”. Khandekar \& Sharma (2005) point out if organizations are seeking competitive advantage through HR, they should design HR systems in ways that allow them to leverage and exploit knowledge-based resources and enable employees to use the knowledge for competitive edge. Thus, the discussion leads to:

Proposition 1: Human resource management practices have positive association with organizational learning capability.

\subsubsection{Leadership}

A review of the literature on leadership reveals that there are many studies on measurement of leadership but the association 
of leadership and organizational learning capability has seldom been studied (Chau, 2008, Mirkamali, Alami \& Thani, 2011). Of the human resource-related aspects, this study shall concentrate on support leadership (Montes, et al., 2005). Bontis et al.(2002); Berson et al.(2006); Zagorzek et al.(2009)\& Amy (2008) argued that leadership and organizational learning have limited systematic research directly linking leadership and learning and they remained disconnected fields.

Although there is widespread presumption that leaders are the catalyst or powerful facilitators of organizational learning (Lakhani, 2003; Zagorzek, et al., 2009), there is little research focusing on the specific practices through which leaders affect organizational learning (Lahteenmaki et al., 2001). As literatures prevailed, Vera \& Crossan (2004) were among the early research that systematically linked leadership and organizational learning. However, they focused mainly on leadership at the upper echelons of organizations.

Extensive and large portion of leadership research state that transformational leadership seems to be strong prerequisite for organizational learning (see (Vera \& Crossan, 2004); Malik et al., 2012; Mirkamali et al, 2011; Camps \& Rodríguez, 2011; García-Morales et al., 2012 \&Zagoršek et al., 2009). However, as one of the notable researcher in transformational leadership style, Bass (1999) proposed that since most organizations need to keep learning at all levels in order to adapt to their changing environments, servant leadership should be of interest for today's organizational leaders for it enables and empowers people to learn and grow. Senge (1990) emphasized the importance of the concept by stating that he believes the essay by Robert Greenleaf (year), titled The Servant as Leader, is the most useful statement on leadership in the last 20 years. This claim by such an influential author begged more empirical study of the emerging theory of servant leadership (Drury, 2004).

Covey (2002) believed servant leadership requires humility of character and core competency built around new skills. Covey (2002) recommended a servant leader approach view that "you don't just serve, you do it in a way that makes them independent of you, and capable and desirous of serving other people" (p. 31). Mittal \& Dorfman (2012) asserted that even though servant leadership is a relatively new construct in the leadership literature appearing in the writings of Greenleaf (1970), it has its origin far earlier, in religion and philosophy. Current models of servant leadership are anchored in the human drive to bond with others and contribute to the betterment of the society. In Islam ("the leader of a people is their servant") and other world religions have long embraced the philosophy of servant leadership. Melcha \& Bosco (2010) found that one criticism of servant leadership has been its lack of support from "published, well designed, empirical research". Therefore, acceptance of the theory has not been strong enough to generate widespread acceptance (Russell \& Stone, 2002). Thus, the discussion leads to:

Proposition 2: Servant leadership has positive association with organizational learning capability.

\subsubsection{Organizational structure}

The conception of the organizational structure construct has come a long way since it was first established by Porter and Lawler (1965). Hage and Aiken (1967) had later simplified the conceptualization of the organizational structure construct. According to Hage and Aiken (1967), organizational structure has been defined as practices being undertaken in an organization with regard to policies, procedures, and rules. Two important features of organizational structure are formalization and centralization, which can further be subdivided into four subdimensions: decision-making, hierarchy of authority, job codification, and rule observation (Hage \& Aiken, 1967). Johari, Yahya \& Omar (2011) noted that the role of organizational structure as a determinant of various workplace outcomes is evident in many empirical findings. The configuration of organizational structure impedes or facilitates the capacity of the company to adapt to change, to learn, to innovate or to improve its ability to generate added value for its customers (MartínezLeón \& Martínez-García, 2011). As early as(Slater \& Narver, 1995; Fiol \& Lyles (1995)study, they considered the relationship between organizational structure and organizational learning. Fiol \& Lyles (1995) viewed that a flexible, decentralized and organic organizational structure seems to be linked to promotion of learning in organizations, and reinforced the idea that an organization could be designed in a way that encourages learning. However, Shipton, Dawson \& West (2002) found a negative relationship between centralized structures and organizational learning mechanisms. In more recent study, Rebelo \& Gomes (2011) found that organizational structure empirically tested to be the conditioning factor to the organizational learning, but in the organizational culture context. Likewise, Martínez-León \& Martínez-García (2011) studied the link between organizational structure and organizational learning. However, the research centers on organizational learning process rather than culture. They posited that organizational structure plays a fundamental role in a company's capacity to identify the knowledge sources needed, acquiring new knowledge, integrating it into the organization and recognizing its absorptive capacity. Consequently, the organizational structure is very important in how firms process knowledge. Therefore, considering the important points of organizational structure as a decisive in the development organizational learning, the discussion leads to:

Proposition 3: Organizational learning has positive association with organizational learning capability.

\subsection{The consequences of organizational learning capability}

\subsubsection{Organizational commitment}

Retaining valued and committed employee to the organization is a top priority for many contemporary organizations today (Neininger et al., 2010; Hausknecht et al., 2009). Valued or top performers are not limited to higher management, but can be 
found at all levels of an organization (Neininger et al., 2010). Organizational commitment is one of the main reasons for these employees to stay (Hausknecht et al., 2009). Therefore organizations necessitate to extend their learning capability and competencies to be able to learn better and faster from their successes and failures, from within and from outside such that will increase the organizational commitment (Zollo \& Winter, 2002).

Organizations are not disappearing; they may be becoming leaner, but they must maintain a core of people who 'are' the organization. As organization becomes smaller and jobs become more flexible, those who remain in the organization become even more important. Once the "fit" is gone, the remaining employees represent the "heart, brain and muscle" of the organization (Meyer \& Allen, 1997). Thus, over the recent years, many firms try to become an employer of choice, which refers to an organization that outperforms their competition in attracting, developing and retaining people with business required talent (Joo \& McLean, 2006). In the era of rapid change and to keep pace with globalization, securing commitment and retaining skilled employees have become key challenges for an organization to gain competitive advantage (Joo \& Park, 2010; Suman \& Srivastava, 2012\& Kalyar et al., 2012). The cost associated with losing key employees, or retaining less productive ones in depressed economic conditions, has long been recognized by organizational leaders. Thus, undesired turnover and underproductive employees have a negative impact on firm profitability (Doh et al., 2011).

Organizational learning researchers have traditionally examined organizational commitment as a focused sub attitudinal facet where commitment is seen as a necessary pre requisite for successful change management (Massingham \& Diment, 2009). This approach typically characterizes organizational commitment as buy in and attitudes are measured in terms of willingness to accept a specific change initiative. Garvin (1993) posited organizational learning as one of the key contextual components to enhance organizational commitment. Basically it refers to an organization skilled at creating, acquiring and transferring knowledge, and at modifying its behavior to reflect new knowledge and insight. More research about the impact of organizational learning on employees' organization commitment is recommended. Many researchers linked organizational learning and organizational performance, see Khandekar \& Sharma (2005); Michna (2009), but little attention has been given to relate organizational learning with organizational commitment, thus more research is required to analyze the relationships between organizational learning and issues concerning employees, such as organizational commitment (Chiva et al., 2007). Thus, the discussion leads to:

Proposition 4: organizational learning capability has positive association with organizational commitment.

\subsection{Organizational learning as mediating variable}

The existing management and leadership research has demonstrated the effects of human resource management practices, leadership, and organizational learning on organizational commitment separately. However, researchers have not yet measured the relationship between human resource management practices, leadership style and organizational structure on organizational commitment as mediated by organizational learning capability. Guchait \& Cho (2010) stressed that although previous studies have suggested e.g., human resource management practices are related to organizational commitment, some scholars have found that these relations are not necessarily direct. Meyer \& Smith (2000) posited that the assumption of a direct influence of the implementation of a particular human resource management practices on employees' organizational commitment cannot be made. (Theriou \& Chatzoglou, 2008) added that there is still little understanding of the mechanisms through which human resource management practices influence organizational effectiveness. Therefore, the question of "how" best human resource management practices lead to organizational performance needs to be answered and the exact mechanics that play an important role must be identified. (Tremblay et al., 2010) suggested that an exchange mechanism must intervene upstream for human resource management practices in influencing organizational commitment. Thus, the discussion leads to: Proposition 4: Organizational learning capability mediates the relationship between human resource management practices, servant leadership and organizational commitment.

Based on the above statements and recognizing that only a few studies centered on its determinants have been carried out, the aim of this research is to examine the relationship between the human resource management practices and servant leadership and the role of learning that could act as potential determining or facilitating factors. Further research is also aimed at examining organizational commitment as the consequence variable of organizational learning. Beside, from the preliminary review of the literature, to the extent of author's knowledge, there appears to be no research that examined the relationship between human resource management practices, servant leadership and organizational commitment, mediated by organizational learning capability.

\section{CONCEPTUAL FRAMEWORK}

The significant importance of organizational learning has received significant attention among researchers and practitioners but there is a few cumulative and empirical research which leads to the development of the proposed conceptual model drawing from previous studies. Thus, based on the research gaps and argument discussed in this paper, human resource management practices (HRM) and servant leadership (SL) variables are postulated as antecedents of organizational learning capability(OLC), and the impact on organizational learning capability on the organizational commitment (OC) as in Figure 1: 


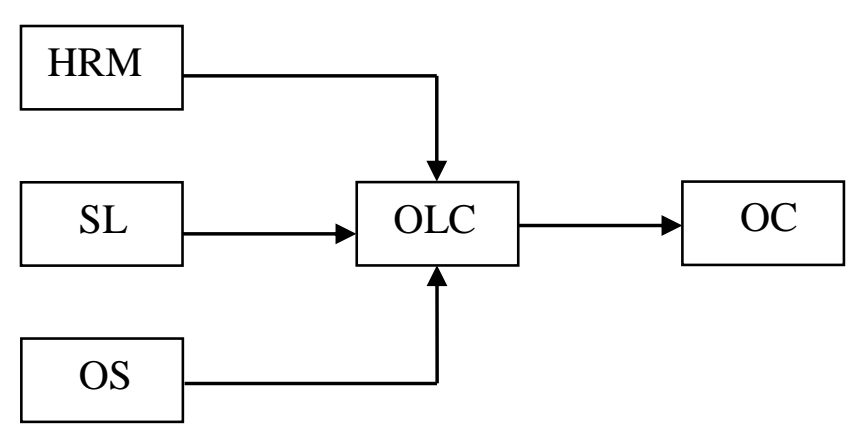

Figure 1. Conceptual framework.

\section{CONCLUSION}

This study extracted examines the issue of organizational learning, which has the potential to impacts on employees' organizational commitment. It is proposed that organizational learning has certain impacts on organizational commitment, which in turn will affect employees' turnover intention. Organizational learning will help the organization to enhance employees' learning capability and it will make the employee have a strong engagement and intention to stay, and become closely attached to the organization. Thus, employee commitment contributes to the fulfillment of overall organization performance. Previous researchers demonstrate that organizational learning is a source of competitive advantage, it offers an alternative paradigm by which systems can change, thus permitting us to redefine the economy and society. In an era of rapid changes in the business world, organizational learning will allow companies to remain flexible, adaptable and innovative, thereby gaining a lasting advantage over their competitors. In Malaysian context, this study could provide initial insight into the nature of the said relationship. It could provide some guidelines for managers to understand the value of learning that could lead to implementation of more effective policies for improving employees' commitment at work.

\section{REFERENCES}

Akgün, A.E., Keskin, H., Byrne, J.C. \&Aren, S. (2007). Emotional and learning capability and their impact on product innovativeness and firm performance. Technovation,27(9): $501-513$

Amy, A.H. (2008). Leaders as facilitators of individual and organizational learning. Leadership \& Organization Development Journal,29(3): 212-234.

Argyris, C. \&Schon, D. (1978). Organizational learning: A theory of action perspective. Reading: Addison-Wesley.

Argyris, C \& Schon, D. (1996). Organizational learning II: theory, method and practice. Reading: Addison-Wesley.

Bass, B.M. (1999). Two decades of research and development in transformational leadership. European Journal of Work and Organizational Psychology,8(1): 9-32.

Berson, Y., Nemanich, L., Waldman, D., Galvin, B.M. \& Keller, R. T. (2006). Leadership and organizational learning: A multiple levels perspective. The Leadership Quarterly17(6): 577-594.

Bhatnagar, J., \& Sharma, A. (2005). The Indian perspective of strategic HR roles and organizational learning capability. The International Journal of Human Resource Management, 16(9): 1711-1739.

Bontis, N., Crossan, M. \& Hulland, J. (2002). Managing an organizational learning system by aligning stocks and flows. Journal of Management Studies 39(4): 437-469.

Budhwar, P. \&Boyne, G. (2004). Human Resource Management in the Indian Public and Private Sectors: An Empirical Comparison. The International Journal of Human Resource Management 15(2): 346-70.

Camps, J. \&Rodriguez, H. (2011). Transformational leadership, learning and employability: effects on performance among faculty members. Personnel Review 40(4): 423-442

Chau, S.L. 2008. Organizational learning (Analysis). International Journal of Strategic Management 8(1).

Chiva, R., Alegre, J., \& Lapiedra, R. (2007). Measuring organisational learning capability among the workforce. International Journal of Manpower 28(3/4): 224-242.

Covey, S.R. (2002). Servant-leadership and community leadership in the twenty-first century. In L.C. Spears \& M. Lawrence (Eds.), Focus on leadership: servant-leadership for the 21st century (27-33). New York: John Wiley \& Sons.

Crossan, M.M., Lane, H.W. \& White, R.E. (1999). An organizational learning framework: From intuition to institution. Academy of Management Review24(3): 522-537.

Crossan, M.M., Lane, H.W., White, R.E., \& Djurfeidt, L. (1995). Organizational Learning: Dimensions for a theory. The International Journal of Organizational Analysis 3(4): 337-360.

Doh, J.P., Smith, R.R., Stumpf S.A, \&Tymon Jr, W.G. (2011). Pride and professionals: Retaining talent in emerging economies. Journal of Business Strategy 32(5): 35-42.

Drury, S. (2004). Employee perceptions of servant leadership: Comparisons by level and with job satisfaction and organizational commitment.Virginia Beach: Regent University.

Fiol, C. M., \& Lyles, M. A. (2007). Organizational Learning, 10(4), 803-813.

García-Morales, V.J., Jiménez-Barrionuevo, M.M., \& Gutiérrez-Gutiérrez, L. (2012). Transformational leadership influence on organizational performance through organizational learning and innovation. Journal of Business Research 65(7): 1040-1050.

Garvin, D.A. (1993). Building a learning organization. Harvard Business Review 71(4): 78-91.

Greenleaf, R.K. (1970). The servant as leader. Indianapolis, ST: The Robert K. Greenleaf Center.

Goh, S.\& Richards, G. (1997). Benchmarking the learning capability of organizations. European Management Journal 15(5): 575-583.

Guchait, P. \& Cho, S. (2010). The impact of human resource management practices on intention to leave of employees in the service industry in India: The mediating role of organizational commitment. The International Journal of Human Resource Management 21(8): 1228-1247.

Hage, Jerald \& Aiken, M. (1967). Program Change and Organizational Properties: A Comparative Analysis, American Journal of Sociology, 72 (March), 503-19.

Hausknecht, J.P., Rodda, J \& Howard, M.J (2009). Targeted employee retention: Performance-based and job-related differences in reported reasons for staying. Human Resource Management 48(2): 269-288.

Hult, G.T.M. \&Ferrell, O.C. (1997). Global Organizational Learning capability in purchasing: construct and measurement.Journal of Business Research40: 97-111. 
Jaw, B.S., \& Liu, W. (2003). Promoting organizational learning and self-renewal in Taiwanese companies: The role of HRM. Human Resource Management 42(3): 223-241.

Johari, J., Yahya, K.K. \&Omar, A. (2011). The Construct Validity of Organizational Structure Scale:Evidence from Malaysia. World Journal of Management, 3(2), 131-152.

Joo, B. \& Park, S. (2010). Career satisfaction, organizational commitment, and turnover intention: The effects of goal orientation, organizational learning culture and developmental feedback. Leadership \& Organization Development Journal 31(6): 482-500.

Joo, B. \& McLean, G.N. (2006). Best employer studies: A conceptual model from a literature review and a case study. Human Resource Development Review 2(1): 228-57.

Jerez-Gómez, P., Céspedes-Lorente, J., \& Valle-Cabrera, R. (2005). Organizational learning capability: a proposal of measurement. Journal of Business Research58(6): 715-725.

Kalyar, M.N., Rafi, N. \& Ahmad, B. (2012). Organizational learning and organizational commitment: A correlational study in manufacturing context. African Journal of Business Management 6(9): 3349-3355.

Khandekar, A., \& Sharma, A. (2005). Organizational learning in Indian organizations: a strategic HRM perspective. Journal of Small Business and Enterprise Development, 12(2): 211-226.

Kong, E., Chadee, D. \& Raman, R. (2012). Managing Indian IT professionals for global competitiveness: the role of human resource practices in developing knowledge and learning capabilities for innovation. Knowledge Management Research \& Practice 1(12).

Lahteenmaki, S., Toivonen, J.\& Mattila, M. (2001). Critical aspects of organizational learning research and proposal for its measurement. British Journal of Management 12(1): 113129.

Lakhani, M.A. (2005). Relational linkages between visionary leadership and organizational learning across the United States, Malaysia and India. Phoenix: University of Phoenix.

López-Cabrales, Á., Real, J.C.\& Valle, R. (2011). Relationships between human resource management practices and organizational learning capability: The mediating role of human capital. Personnel Review 40(3): 344-363.

Lee, V.H,Ooi, K.B, Chong, A.Y \& Tan, B.I. (2011). HRM practices and organizational learning: a critical review and research agenda. International Journal of Innovation and Learning 10(4).

Malik, M.E., Danish, R.Q. \& Munir, Y. (2012). The Role of Transformational Leadership and Leader's Emotional Quotient in Organizational Learning. World Applied Sciences Journal16(6): 814-818.

Martínez-León, I.M., \&Martínez-García, J.A. (2011). The influence of organizational structure on organizational learning. International Journal of Manpower 32(5/6): 537-566.

Massingham, P. \& Diment, K. (2009). Organizational commitment, knowledge management interventions, and learning organization capacity. The Learning Organization 16(2): 122-142.

Melchar, D.E. \& Bosco, S.M. (2010). Achieving High Organization Performance through Servant Leadership. The Journal of Business Inquiry 9(1): 74-88.

Meyer, J.P \& Allen, N.J. (1991). A three component conceptualization of organizational commitment. Human Resource Review 1(1): 61-89.

Meyer, J. P., \& Allen, N.J. (1997). Commitment in the workplace: Theory, research, and application. Thousand Oaks, CA: Sage.

Meyer, J.P. \& Smith, C.A. (2000). HRM Practices and Organizational Commitment: Test of a Mediation Model. Canadian Journal of Administrative Sciences 17(4): 319-331.
Meyer, J.P., Stanley, D.J., Herscovitch, L. \& Topolaytsky, L. (2002). Affective, continuance, and normative commitment to the organization. Journal of Vocational Behavior 61(1): 20-52.

Michna, A. (2009). The relationship between organizational learning and SME performance in Poland. Journal of European Industrial Training 33(4): 356-370.

Mirkamali, S.M., Thani, F.N. \& Alami, F. (2011). Examining the Role of Transformational Leadership and Job Satisfaction in the Organizational Learning of an Automotive Manufacturing Company. Procedia - Social and Behavioral Sciences 29(1): 139-148.

Mittal, R., \&Dorfman, P.W. (2012). Servant leadership across cultures. Journal of World Business 47(4): 555-570.

Montes, F.J., Ruiz-Moreno, A.\&García-Morales, V. (2005). Influence of support leadership and teamwork cohesion on organizational learning, innovation and performance: an empirical examination. Technovation 25(10): 1159-1172.

Morrison, E.W. (1993). New comer information seeking: Exploring types, modes, sources, and outcomes. Academy of Management Journal 36(3): 557-589.

Neininger, A., Lehmann-Willenbrock, N., Kauffeld, S.\&Henschel, A. (2010). Effects of team and organizational commitment - A longitudinal study. Journal of Vocational Behavior 76(3): 567-579.

Perez-Lopez, S., Montes-Peon, J.M., \& Vazquez-Ordas, C.J. (2005). Human Resource Practices, Organizational Learning and Business Performance. Human Resource Development International 8(2): 147-164.

Porter, L. W., \& Lawler, E. E., III.(1965). Properties of organization structure in relation to jobattitudes and job behavior. Psychological Bulletin, 1965, 64, 23-51.

Probst, G. (1997). Organizational learning: The competitive advantage of the future. Europe: Prentice Hall.

Rebelo, T.M. \& Gomes, A.D. (2011). Conditioning factors of an organizational learning culture. Journal of Workplace Learning 23(3): 173-194.

Robert F., Russell, A.\& Stone, G.(2002). A review of servant leadership attributes: developing a practical model.Leadership \& Organization Development Journal23(3): 145-157.

Santos-Vijande, M., Lopez-Sanchez, J.A. \&Trespalacios, J.A (2012). How organizational learning affects a firms' flexibility, competitive strategy, and performance. Journal of Business Research65(1): 1079-1089.

Sashkin, M. (2003). Leadership that matter: The critical factors for making a difference in people's life and organizations' success. San Fransicso: Berrett-Koehler.

Schulz, M. (2001). Organizational Learning. In Joel A. C. Baum (Eds.), Companion to Organizations. Washington: Blackwell Publishers.

Senge, P.M. (1990). The Fifth Discipline : The Art and Practice of the Learning Organization. London: Random House Business Books.

Senge, P.M., Kleiner, A., Roberts, C., Ross, R.B., \& Bryan J. (1994). The Fifth DisciplineNew York: Fieldbook.

Shipton, H., Dawson, J. \& West, M. (2002). Learning in Manufacturing Organizations:What Factors Predict Effectiveness?.Human Resource Development International 5(1): 5572.

Slater, S. F., \& Narver, J. C. (1995). Market Orientation and the Learning Organization. Journal of Marketing, 59(3), 63.

Smith, P.A.C (2012). The importance of organizational learning for organizational sustainability. The Learning Organization 19(1): 4-10.

Suman, S. \& Srivastava, A.K. (2012). Antecedents of Organisational Commitment across Hierarchical Levels. Psychology \& Developing Societies 24(1): 61-83. 
Taylor, G.S., Templeton, G.F. and \& L.T. (2010). Factors Influencing the Success of Organizational Learning Implementation: A Policy Facet Perspective. International Journal of Management Reviews 12(1): 353-364.

Theriou, G.N.\&Chatzoglou, P.D. (2008). Enhancing performance through best HRM practices, organizational learning and knowledge management: A conceptual framework. European Business Review 20(3): 185-207.

Tremblay, M., Cloutier, J., Simard, G., Chênevert, D. \& Vandenberghe, C. (2010). The role of HRM practices, procedural justice, organizational support and trust in organizational commitment and in-role and extra-role performance. The International Journal of Human Resource Management 21(3): 405-433.

Ussahawanitchakit, P. (2008). Organizational learning capability, organizational commitment, and organizational effectiveness: An empirical study of Thai accounting firms. International Journal of Business Strategy 8(3): 1-13.

Vera, D. \& Crossan, M. (2004). Strategic leadership and organizational learning.Academy of Management Review29(2): 222-240.

Yeung, A.K., Ulrich, D.O., Nason, S.W. \&Glinow, M.A. (1999). Organizational learning capability. New York: Oxford University Press.

Zagoršek, H., Dimovski, V.\& Škerlavaj, M. (2009). Transactional and transformational leadership impacts on organizational learning Journal for East European Management Studies 144-166.

Zollo, M. \& Winter, S.G. (2002). Knowledge, knowing, and organizations: Deliberate learning and the evolution of dynamic capabilities. Organization Science 13(1): 339-351. 